\title{
Coagulation and Fibrinolysis Activation Markers in Prostatic Carcinoma Patients
}

\author{
Remy W. F. Geenen ${ }^{1}$, Karl P. J. Delaere ${ }^{1}$ and Jan W. J. van Wersch ${ }^{2}$ \\ 1 Department of Urology, \\ 2 Department of Haematology, \\ De Wever Hospital, Heerlen, The Netherlands
}

Summary: In 49 patients with benign prostatic hyperplasia, 24 metastatic prostatic carcinoma patients all under palliative hormonal treatment, 17 untreated prostatic carcinoma patients without metastases and 14 untreated prostatic carcinoma patients with metastases, plasma levels of thrombin-antithrombin III complex, D-dimer and plasmin$\alpha_{2}$-antiplasmin were determined.

The coagulation activation marker thrombin-antithrombin III complex did not show any significant difference between the different patient groups. Of the fibrinolysis markers, D-dimer levels were elevated in both metastatic groups compared to the non-metastatic group and the benign prostatic hyperplasia group. Surprisingly, the levels of the other fibrinolysis marker, plasmin- $\alpha_{2}$-antiplasmin, showed no significant difference. The nature of these findings is discussed and related to other relevant literature. The general conclusion is that fibrinolysis may not play such a prominent role in prostatic carcinoma as described and expected.

\section{Introduction}

Prostatic carcinoma can affect the coagulation and fibrinolytic system $(1,2)$. The first report on coagulation abnormalities in a patient with a prostatic carcinoma was published more than 60 years ago (3). In the last decades, attention was drawn to coagulation and fibrinolysis abnormalities in patients with prostatic carcinoma treated with estrogens. Estrogen treatment in patients with prostatic carcinoma is associated with a significant decrease in antithrombin III (4). Coagulation and fibrinolysis abnormalities in non-treated patients or nonestrogen treated patients with prostatic carcinoma, have not been addressed frequently. In the present study, coagulation and fibrinolysis activation (fig. 1) was determined in patients with prostatic carcinoma, non-estrogen hormonally treated or non-treated, and in patients with benign prostate hypertrophy. Coagulation activation was assessed by the thrombin-antithrombin III complex, a sensitive marker which indicates generation of thrombin in vivo (5). The fibrinolytic system activity was evaluated by measuring the D-dimer and the plasmin- $\alpha_{2}$ antiplasmin. D-dimer is produced as a result of cleavage of cross-linked fibrin by plasmin. D-dimer reflects in vivo plasmin-induced fibrinolysis (6). Plasmin- $\alpha_{2}$-antiplasmin is a relatively new assay and a sensitive marker for plasmin generation in vivo (5). In the last few years some studies were published in which plasmin- $\alpha_{2}$-antiplasmin was determined in patients with different kinds of solid tumours, arterial thromboembolism and dissem- inated intravascular coagulation with a variety of underlying diseases $(5-8)$. To our knowledge, plasmin- $\alpha_{2}-$ antiplasmin was never measured before in a group of patients with prostatic carcinoma.

\section{Materials and Methods}

Patients

All patients visited the urological outpatient department. In every prostatic carcinoma patient, the diagnosis was proven after histological examination of prostatic tissue. This tissue was obtained by means of prostatic biopsy. These patients underwent an abdominal CT-scan, a bone scan and a chest X-ray for further staging. In some patients the prostatic carcinoma was discovered after a transurethral prostate resection for benign prostatic hyperplasia. The histological examination of the resected prostate chips, however, showed a small adenocarcinoma. These patients underwent the same investigations for further staging.

The diagnosis of benign prostate hypertrophy was made when the patient presented with complaints of prostatism, when rectal examination revealed a benign prostate and a flowmetry showed a maximum flow rate of less than $10 \mathrm{ml} / \mathrm{s}$.

Patients taking anticoagulant drugs and patients with a history of bleeding or thrombo-embolic disease were excluded.

The patients with benign prostate hypertrophy formed a group of 49 patients (group 1). The 55 patients with prostatic carcinoma were divided into 3 groups. Group 2 consisted of 24 patients who had lymphatic and/or haematologic metastases and who were being hormonally treated at the time of blood sample taking. Twelve patients received gonadoreline analogues, nine patients anti-androgens and three patients estramustine phosphate. The median duration of the hormonal therapy was 25 months $(25-75$ th percentile: 8-43 months). Group 3 consisted of 17 patients without lymphatic and/or haematologic metastases who had not received any kind of treatment at the time of blood sample taking. Patients with lym- 


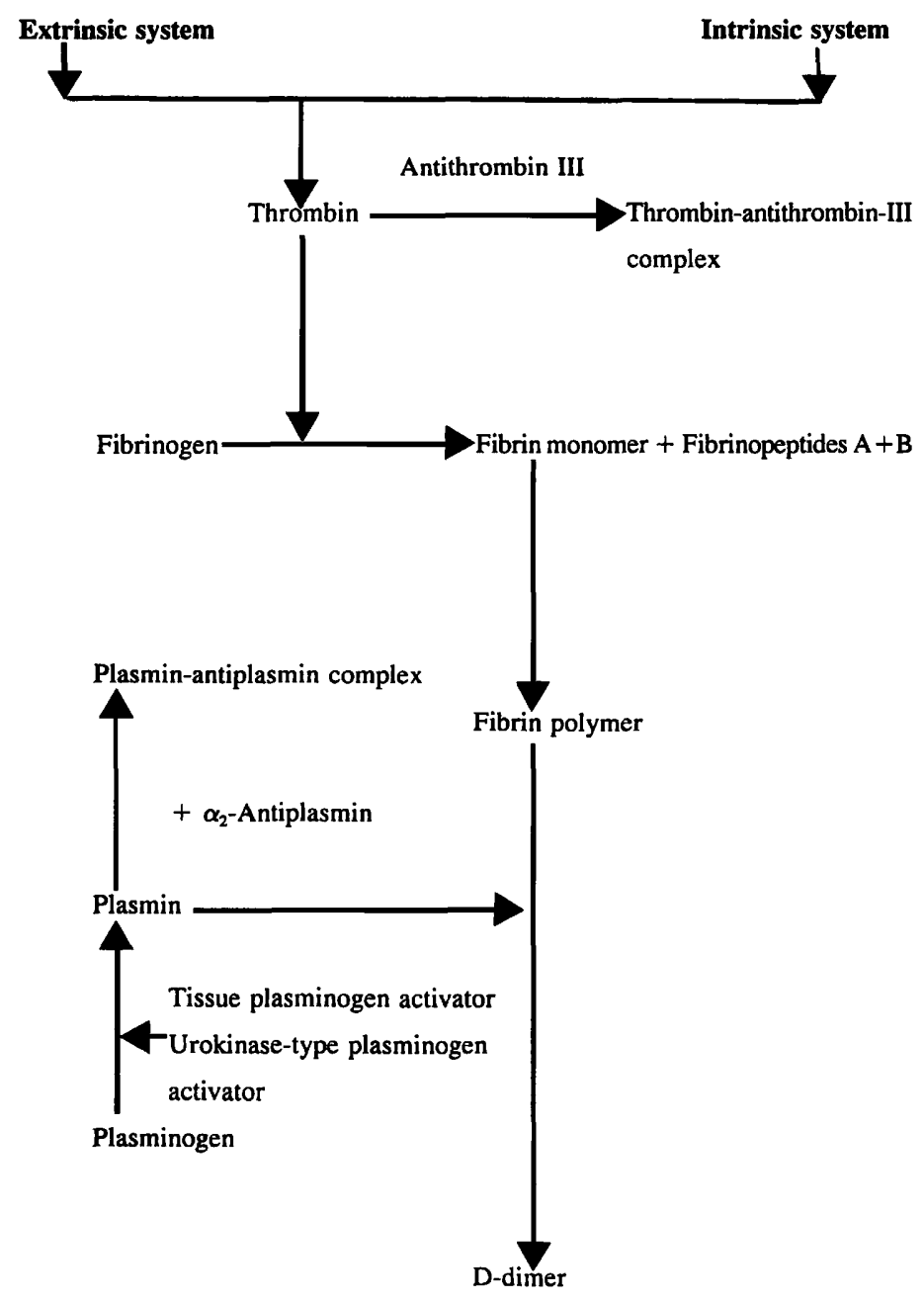

Fig. 1 Relevant part of the coagulation and fibrinolysis cascade.

phatic and/or haematologic metastases who had not received any kind of treatment at the time of blood sample taking formed group 4 (14 patients). In all patients, the haematological metastases were bone metastases.

\section{Samples and methods}

Blood samples were drawn from a cubital vein in sitting position before any prostatic manipulation took place. The various constituents were determined in citrated plasma. This was prepared by centrifugation of a mixture of nine volumes freshly drawn blood with one volume trisodium citrate $(0.11 \mathrm{~mol} / \mathrm{l})$ during 30 minutes $(1600 \mathrm{~g})$ at $25^{\circ} \mathrm{C}$. The plasma was stored at $-70^{\circ} \mathrm{C}$ in plastic tubes and thawed at $37^{\circ} \mathrm{C}$ for 5 minutes before batch analysis.

For the thrombin-antithrombin III complex determination, an Elisa test kit was used (Behring Corporation, Marburg, Germany) (intraassay $\mathrm{CV}=7.1 \%$ ). The fibrin degradation products were measured by means of the D-dimer test of the Behring Corporation (Marburg, Germany) (intra-assay $\mathrm{CV}=4.9 \%$ ).

For the plasmin- $\alpha_{2}$-antiplasmin measurements, the Elisa test kit Enzygnos ${ }^{\circledR}$ plasmin- $\alpha_{2}$-antiplasmin of the Behring Corporation (Marburg, Germany) was employed (intra-assay $\mathrm{CV}=5.4 \%$ ). As a reference point, additionally, prostate-specific antigen was determined in serum by the method of Pharmacia Delfia PSA (Rubi Pharmacia, Woerden, The Netherlands).

\section{Statistics}

The Mann-Whitney-Wilcoxon test for paired samples and the $\chi^{2}$ test, where appropriate, were used. A p-value less than 0.05 was considered to be statistically significant.

\section{Results}

The median values and p-values are listed in table 1 and the proportions of decreased or increased values and $p$ values are listed in table 2.

No significant difference in thrombin-antithrombin II complex values was found between the different groups. A trend toward significance though, was found between the untreated group with metastases and the benign prostate hypertrophy group. Thrombin-antithrombin III complex was higher in the untreated cancer group with metastases compared to the benign prostate hypertrophy group and the p-value was nearly significant $(0.08)$. A significantly larger proportion of both metastatic groups had increased thrombin-antithrombin III complex and D-dimer values compared to the benign prostate hypertrophy group and the non-metastatic group.

The D-dimer levels showed significant differences between the benign prostate hypertrophy group and the treated group with metastases $(p<0.05)$, between the treated group with metastases and the untreated group without metastases $(p<0.01)$ and between both untreated groups $(p<0.05)$. In all cases, D-dimer levels were significantly higher in the metastatic cancer 


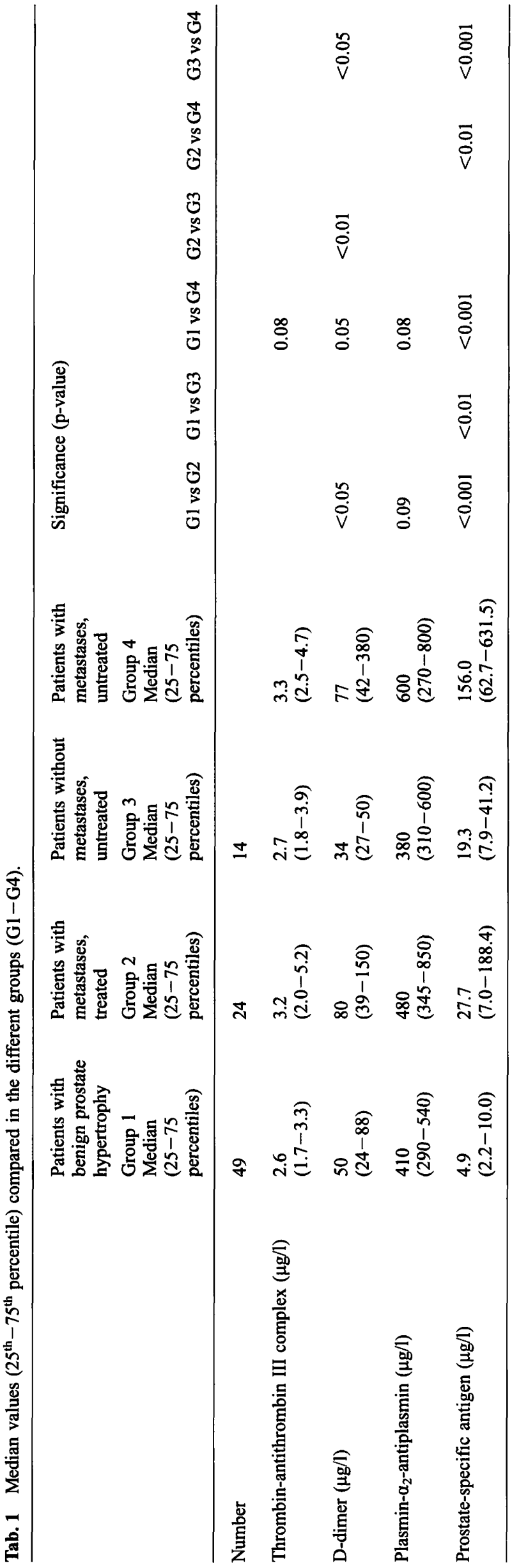

groups. A borderline significant difference was found between the benign prostate hypertrophy group and the untreated group with metastases $(p=0.05)$.

No significant difference was found between the median plasmin- $\alpha_{2}$-antiplasmin levels of the different groups. Plasmin- $\alpha_{2}$-antiplasmin was higher in both metastatic groups compared to the benign prostate hypertrophy group and the p-value was nearly significant, 0.09 for benign prostate hypertrophy versus treated metastatic group and 0.08 for benign prostate hypertrophy versus untreated metastatic group. The metastatic cancer group without treatment had significantly more patients with increased plasmin- $\alpha_{2}$-antiplasmin levels compared to all three other groups.

\section{Discussion}

It has been reported that fibrinolysis seems to play a prominent role in (metastatic) prostatic carcinoma, as indicated by increased D-dimer levels and increased urokinase-type plasminogen activator levels in the blood of patients with (metastatic) prostatic carcinoma $(1,2$, $9,10)$. In our patient groups, increased D-dimer levels were found in the treated cancer group with metastases. Between the two untreated cancer groups, the D-dimer levels were higher in the group with metastases compared to those in the group without metastases.

Surprisingly, the plasmin- $\alpha_{2}$-antiplasmin levels did not show an increase. This might be a methodological problem as a result of the action of neutrophil elastase, which is enhanced in carcinoma patients. Elastase can degrade fibrin so that similar, but not identical, fibrin split products are formed and the trigger for reactive plasmin$\alpha_{2}$-antiplasmin formation is not really strong. On the other hand it has been reported that D-dimer test kits detect both plasmin- and neutrophil elastase-derived split products (11). So, there are two pathways, which supply substances reacting in the D-dimer test and only one pathway in which plasmin- $\alpha_{2}$-antiplasmin formation is provoked. This might explain why significantly increased median $\mathrm{D}$-dimer values have been found and were found in the present study in patients with prostatic carcinoma and no significant increase in median plasmin- $\alpha_{2}$-antiplasmin values was found in prostatic carcinoma patients in the present study.

To our knowledge, there has been only one study published in which thrombin-antithrombin III complex was measured in patients with prostatic carcinoma (1). Thrombin-antithrombin III complex was higher in the prostatic cancer group compared to two control groups, but no p-value was mentioned. The cancer group consisted of 51 patients with different stages of prostatic carcinoma. One control group consisted of 40 blood donors and the other of 20 patients with benign prostate 
Tab. 2 Proportions of decreased (D) or increased (I) values (\%) in the various patients groups.

\begin{tabular}{|c|c|c|c|c|c|c|c|c|c|c|}
\hline \multirow[t]{2}{*}{ Analytes } & \multirow{2}{*}{\multicolumn{2}{|c|}{ (Reference values) }} & \multicolumn{2}{|c|}{$\begin{array}{l}\text { Patients with } \\
\text { benign prostate } \\
\text { hypertrophy } \\
\text { Group } 1\end{array}$} & \multicolumn{2}{|c|}{$\begin{array}{l}\text { Patients with } \\
\text { metastases, } \\
\text { treated } \\
\text { Group } 2\end{array}$} & \multicolumn{2}{|c|}{$\begin{array}{l}\text { Patients with- } \\
\text { out metastases, } \\
\text { untreated } \\
\text { Group } 3\end{array}$} & \multicolumn{2}{|c|}{$\begin{array}{l}\text { Patients with } \\
\text { metastases, } \\
\text { untreated } \\
\text { Group } 4\end{array}$} \\
\hline & & & D & I & D & I & $\mathrm{D}$ & I & $\mathrm{D}$ & I \\
\hline $\begin{array}{l}\text { Thrombin-antithrombin III } \\
\text { complex }\end{array}$ & \multicolumn{2}{|c|}{$(1.04-4.1 \mu \mathrm{g} / \mathrm{l})$} & 0 & 12.2 & 0 & 29.2 & 0 & 5.9 & 0 & 35.7 \\
\hline Plasmin- $\alpha_{2}$-antiplasmin & \multicolumn{2}{|c|}{$(50-500 \mu \mathrm{g} / \mathrm{l})$} & 0 & 28.6 & 0 & 41.6 & 0 & 29.4 & 0 & 57.0 \\
\hline D-dimer & \multicolumn{2}{|c|}{$(<80 \mu \mathrm{g} / \mathrm{l})$} & - & 32.7 & - & 50.0 & - & 11.8 & - & 42.9 \\
\hline \multicolumn{2}{|c|}{$\begin{array}{l}\text { Thrombin-antithrombin III complex } \\
\text { G1 vs G2: } p<0.005 \\
\text { G1 vs G3: } n . s . \\
\text { G1 vs G4: } p<0.001 \\
\text { G2 vs G3: } p<0.001 \\
\text { G2 vs G4: n.s. } \\
\text { G3 vs G4: } p<0.001\end{array}$} & $\begin{array}{l}\text { D-dimer } \\
\text { G1 vs G2: } \\
\text { G1 vs G3: } \\
\text { G1 vs G4: } \\
\text { G2 vs G3: } \\
\text { G2 vs G4: } \\
\text { G3 vs G4: }\end{array}$ & $\begin{array}{l}<0 . \\
<0 . \\
<. \\
<0 . \\
<0 .\end{array}$ & & $\begin{array}{l}\text { nin-c } \\
\text { s G2 } \\
\text { s G3 } \\
\text { s G4 } \\
\text { s G3 } \\
\text { s G4 } \\
\text { s G4 }\end{array}$ & $\begin{array}{l}\text { tiplasm } \\
<0.00 \\
<0.01 \\
\text { s. } \\
<0.00\end{array}$ & & & & \\
\hline
\end{tabular}

hypertrophy. The present study was not able to confirm the results found by others. First, no coagulation pathway activation and fibrin formation has ever been described in prostatic carcinoma (12). Therefore, the coagulation activation in prostatic carcinoma patients found by others, may have a cause other than the prostatic carcinoma. Second, the fibrinolysis marker D-dimer showed significance in the present study and other

\section{References}

1. Oliver A, Iglesias JM, Zuazu-Jausoro I, Parramon I, Laguna $\mathrm{P}$, Fontcuberta J. Activation of coagulation and fibrinolysis in prostatic neoplasms [abstract]. Thromb Haemostasis 1991; 65:1054.

2. Adamson AS, Francis JL, Witherow RO, Snell ME. Coagulopathy in the prostate cancer patient: prevalence and clinical relevance. Ann R Coll Surg Engl 1993; 75:100-4.

3. Jurgens R, Trautwein H. Über Fibrinopenie beim Erwachsenen, nebst Bemerkungen über die Herkunft des Fibrinogens. Dtsch Arch Klin Med 1930; 169:28-43.

4. Büller HR, Boon TA, Henny CP, Dabhoiwala F, Ten Cate JW. Estrogen-induced deficiency and decrease in antithrombin III activity in patients with prostatic cancer. J Urol 1982; 128:72-4.

5. Uchiyama T, Matsumoto $M$, Kobayashi N. Studies on the pathogenesis of coagulopathy in patients with arterial thromboembolism and malignancy. Thromb Res 1990; 59:955-65.

6. Sagripanti A, Carpi A, Ferdeghini M, Baicchi U, Grassi B. Plasmatic markers of haemostatic system activation in patients with solid neoplasms. J Nucl Med Allied Sci 1990; 34:32132.

7. Nanninga PB, Van Teunenbroek A, Veenhof CHN, Büller HR, Ten Cate JW. Low prevalence of coagulation and fibrinolytic activation in patients with primary untreated cancer. Thromb Haemostasis 1990; 64:361-4. studies. However, the most direct fibrinolysis marker, plasmin- $\alpha_{2}$-antiplasmin, did not. This may be due to the, with other fibrin split products, cross-reacting D-dimer test kits. Thus, fibrinolysis may not play such a prominent role in prostatic carcinoma as described and expected. Before a definite answer can be given to this matter, we think that new studies with larger patient groups are necessary.

8. Kario K, Matsuo T, Kodama K, Matsuo M, Yamamoto K, Kobayashi $\mathrm{H}$. Imbalance between thrombin and plasmin activity in disseminated intravascular coagulation. Assessment by the thrombin-antithrombin-III complex/plasmin-alpha-2-antiplasmin complex ratio. Haemostasis 1992; 22:179-86.

9. Hienert G, Kirchheimer JC, Pflüger H, Binder BR. Urokinasetype plasminogen activator as a marker for the formation of distant metastases in prostatic carcinomas. J Urol 1988; 140:1466-9.

10. Köller A, Kirchheimer J, Pflüger H, Binder BR. Tissue plasminogen activator activity in prostatic cancer. Eur Urol 1984; 10:389-94.

11. Seitz R, Lerch L, Immel A, Egbring R. D-dimer tests detect both plasmin and neutrophil elastase derived split products. Ann Clin Biochem 1995; 32:193-5.

12. Zacharski LR, Wojtukiewicz WZ, Constantini V, Ornstein DL, Memoli VA. Pathways of coagulation/fibrinolysis activation in malignancy. Sem Thromb Hemostasis 1992; 18:104-16.

\section{Received August 7/November 4, 1996}

Corresponding author: Dr. J. W. J. van Wersch, De Wever Hospital, Department of Haematology, P. O. Box 4446, NL-6401 CX Heerlen, The Netherlands 